factor of 10 or more, would take up to 25 years, the report notes.

"If it can be made clear, very soon, that such reduced emissions will be required of aircraft of all nations, and if design to reduce those emissions is incorporated promptly into ongoing engine development, ozone reduction could then be kept near the current reduction due to aircraft alone (less than $0.1 \%$ ) . . . for fleets up to 4,000 747 -class subsonics at $11 \mathrm{~km}(38,000$ feet) or 1,000 at $13 \mathrm{~km}(43,000 \mathrm{feet})$, and for 150 Concorde/TU-144-class SSTs", the report calculates. Over the longer term and with the more radical engine redesign, "stratospheric air travel could expand as a function of demand without affecting the environment adversely, in keeping with deliberate calculable standards enforcement".

The key to those sanguine predictions is early development of international standards to force SST emissions to be lowered. But, given the tortuous history of attempts to regulate emissions from automobiles in the United States, that will be no easy task. Nevertheless, the report argues that "the process of establishing and meeting standards should start now because of the long lead times involved".

As for the biological effects of increased ultraviolet radiation resulting from the operation of SSTs in the stratosphere, the CIAP report states that the percentage increase in ultraviolet flux is about twice the percentage decrease in the lower ozone layer. Thus, the smallest detectable depletion of the ozone layer- $0.5 \%$ - would increase ultraviolet flux by about $1 \%$. Though the effect of such an increase on the incidence of skin cancer is not readily calculated, the report notes that an upper level effect can be calculated by postulating that ultraviolet radiation plays the only role in development of non-melanomic skin cancer. An increase of $1 \%$ in ultraviolet flux would therefore cause an increase of $1 \%$ in the number of skin cancers.

In addition to those suggestions, the CIAP report also notes that another possibly serious problem with a large number of SSTs is that sulphur compounds in jet fuel could end up as solid particles of sulphuric acid floating in the stratosphere. The effect of that would be to filter out some of the solar energy reaching the Earth, which in turn could reduce the mean global temperature. Although it would take a very large fleet of SSTs to produce a detectable effect, the report notes that a difference of only a fraction of a degree would cost hundreds of millions of dollars in crop losses. The report therefore suggests that consideration be given to regulations to force high flying aircraft to use low-sulphur fuels.

\section{India's space programme}

\section{from Narender K. Sehgal, Jullundur}

INDIA's modest space programme is facing rough weather. Until about two to three years ago, things were going fairly well and were not too far behind schedule. Then generally difficult economic conditions, coupled with inflation and rising costs, began to take their toll. Funds have since been scarce and slow in coming, so important projects are running late, and some have had to be curtailed or postponed. Others face an uncertain future as decisions on them are kept pending.

Space research formally began in India with the creation of INCOSPAR (the Indian National Committee for Space Research) in the Department of Atomic Energy (DAE) in 1962. The programme started off with the launchings of sounding rockets from the Thumba Equatorial Rocket Launching Station near Trivandrum, mainly for meteorological and ionospheric investigations in the upper atmosphere. Following administrative and organisational changes over the years, ISRO (the Indian Space Research Organisation), a body under the Department of Space, took over responsibility for all matters relating to the country's space programme in 1969.

From small beginnings in 1963, when the Thumba station became operational, the programme has grown steadily and now covers a whole range of activities relating to rockets and satellites. The Space Science and Technology Centre (SSTC) near Thumba is the research and development unit of ISRO and is responsible for (1) work on systems and their components required in space research; (2) carrying out pilot production of equipment resulting from such work; and (3) developing an indigenous satellite launch capability not only linked to scientific exploration but also to communications, meteorology and remote sensing.

Besides the Thumba station and the SSTC, several other establishments are also engaged in work connected with different aspects of the research programme.

According to original plans, the high spot of India's space programme-the orbiting of an Indian satellite taken up and Indian rocket launched from Indian soil-should have been attained during 1974. By the end of 1972, however it had become quite clear that work on the project was running behind schedule and that the launch would not be possible before 1977. Apparently, the delay was mainly because of difficulties with the satellite launch vehicle project, since in early 1973 it was announced that an Indian satellite would go into orbit in the middle of 1974 atop a Soviet rocket launched from within the Soviet Union. This was to be a much heavier payload than the one planned for an Indian launch. Though good progress has been reported from time to time on the satellite part of this latter project, the launch, first postponed to the end of 1974, has now been rescheduled for sometime during 1975. A satellite prototype was reported sometime ago to have undergone successful tests both at Bangalore and in the Soviet Union. The small delay in launching could be because of either or both of budgetary difficulties and technical reasons, though there are certainly some grounds for thinking that the reasons lie elsewhere.

Sources at the Department of Space and ISRO have flatly denied a report in a British Interplanetary Society journal that India had agreed to make port facilities available to Soviet recovery ships in the Indian Ocean in return for Soviet launching of India's first satellite (weighing about 300 kilograms).

It is acknowledged a request for port facilities, for space tracking and recovery ships, was in fact received from the Soviet Union sometime in 1973. But the sources maintain that no decision has yet been taken in this regard and that this has nothing to do with the Soviet Union's agreement to launch the satellite, the two being entirely separate matters. It is believed that Indian scientists have been invited to instal research instruments in future Soviet space vehicles to the Moon and other planets, but the matter has yct to be discussed and finalised. A joint meeting of the space officials of the two countries is to take place in February this year for discussions on collaboration in space research.

Meanwhile, the Prime Minister recently told a consultative committee meeting that the original cost estimate of Rs15.6 crores sanctioned in 1973 for the satellite launch vehicle project would probably need to be escalated. "Apart from the increased cost, the special circumstances prevailing during the past two to three years have created difficulties in the way of speeding up the progress of the project", it was said. "Barring unforeseen problems, it is possible to achieve a satellite launch in 1978", the committee was informed.

The launch vehicle project is aimed at developing a four-stage rocket to fire a 40-kilogram satellite into orbit 400 kilometres up.

Full allocations of funds for the projects of the Department of Space have not been forthcoming, and this has resulted in an adjustment of priorities. $\square$ 